\title{
Interweave Language and Mathematics
}

\author{
Rashida H. Kapadia \\ Educationalist, Aljamea-tus-Saifiyah, Mumbai, Maharashtra, India.
}

\begin{abstract}
How to cite this paper: Rashida $\mathrm{H}$. Kapadia. (2021). Interweave Language and Mathematics. The Educational Review, USA, 5(10), 391-396.

DOI: 10.26855/er.2021.10.003
\end{abstract}

Received: September 16, 2021

Accepted: October 8, 2021

Published: October 21, 2021

Corresponding author: Rashida $\mathrm{H}$. Kapadia, Educationalist, Aljamea-tus-Saifiyah, Mumbai, Maharashtra, India.

Email: rashidakapadia@hotmail.com

\begin{abstract}
'Learning without Burden' is what the teachers should seek to provide to their students. Framework on elaborating about the pedagogy of mathematics education affirms that the aim of mathematics education should not merely be algorithmic in nature. Students should be able to highlight relationships among ideas and use concepts for problem solving. This entails that learners should be allowed to express understanding of mathematical terms, concepts or relationships in their own words. They should be encouraged to speak mathematically. In order to be able to do so, mathematics teaching should focus on eliciting of these relationships from students. Mathematics is a living subject which seeks to understand patterns that permeate both the world around us and the mind within us. Although the language of mathematics is based on rules that must be learned, it is important for motivation that students move beyond rules to be able to express things in the language of mathematics. This necessitates the use of language in improving understanding of mathematics. Several researchers have supported the view over the years. For instance, Resnick suggests that using everyday language to talk about a range of mathematical relationships and interpretations may result in more meaningful problem solving. Thus a totally different outlook towards how mathematics is taught and assessed in the classrooms is necessitated. Several reforms have already been implemented, yet the way mathematics is dealt with in the classrooms need to be looked into. The discussion derives its genesis from the need to break barriers between language and mathematics as compartmentalized subjects and use them together for improving mathematics teaching and learning. The paper involves a brief discussion on the literature review of researches between mathematics and language. Followed by, a detailed discussion of various strategies that could support the use and development of integrating language in mathematical discussions in the classrooms. An offshoot of integrating mathematics and language in the classroom would be developing interest and appreciation for the subject of mathematics is also posited by the author.
\end{abstract}

\section{Keywords}

Mathematics Education, Language and Mathematics

\section{Introduction}

The nature of mathematics has been a subject of study over years. Two themes defining mathematics come to the fore, one being that of pure mathematics and the other of applied mathematics. According to the purists' view, mathematics as a subject is studied for the pleasure of studying. Words like aesthetic and elegant are important to the purists (Scopes, 1973). The underlying principles, the structure and relationships among concepts form the basis of pure mathematics. In 
view of applied mathematics how the principles and rules of mathematics can be used in the development of mankind is the focus. Applied mathematics seems to be the development of skills more than understanding the underlying principles of the subject. The present system of education, appear to lay more emphasis on the application of the subject. However, mathematics should also be taught as one in its own right, one that inspires and motivates students to generate knowledge. Mathematics as we know is a subject that is both inspiring and useful. This is well expressed in the definition given by Department for Education and Employment, England, (1999), as 'Mathematics is the study of patterns abstracted from the world around us - so anything we learn in math has literally thousands of applications, in arts, in sciences, finance, health and leisure'.

Though the etymological meaning of mathematics is 'inclined to learn' and has nothing to do with numbers or numeracy skills, yet teachers have limited themselves only to the discussion of how sums should be solved in the mathematics classroom. The National Knowledge Commission (NKC) has observed that teachers are the single most important element of the school system and the country is already facing a severe shortage of qualified and motivated school teachers at different levels (NCF, 2005). If the teachers themselves are not motivated or do not have an inclination for the subject, it would be difficult to convince the students of the importance of mathematics as a subject. The question then arises is how to make mathematics interesting and eliminate the phobia from students' mind about mathematics. To bring about this change, mathematics teachers should be informed of the importance of various ways of making teaching of math interesting.

'Learning without Burden' is what the teachers should seek to provide to their students. The framework on elaborating about the pedagogy of mathematics education affirms that the aim of mathematics education should not merely be algorithmic in nature. It suggests that stress must be laid on identifying, expressing and explaining patterns, on estimation and approximation in solving problems, on making connections, and on the development of skills of language in communication and reasoning, apart from computational skills. Mathematics is a living subject which seeks to understand patterns that permeate both the world around us and the mind within us. Although the language of mathematics is based on rules that must be learned, it is important for motivation that students move beyond rules to be able to express things in the language of mathematics (Schoenfeld, 1992, p. 4). It has always intrigued the mathematics teacher to accept and support the importance of language in the understanding of mathematics.

\section{Identifying similarities in mathematics \& language}

Paul Ernest in his book, 'The Philosophy of Mathematics Education' suggests that the aims of teaching mathematics need to include the empowerment of learners to create their own mathematical knowledge. When mathematics is seen in this way it needs to be studied in living contexts which are meaningful and relevant to the learners, including their languages, cultures and everyday lives, as well as their school based experiences. According to the conventionalist view of philosophy of mathematics, the expression of mathematical truths is based on linguistic conventions. Wittgenstein proposes that it is embedded in our socio-linguistic practices, which suggests that the rules followed to understand language are also applicable to mathematics. For example, the use of the term 'and' in understanding the logical statement of 'when A and B are true than C is true'. In this statement, the use of term 'and' is crucial and the way it is used will cause for its final conclusion.

The social constructivist approach also draws from the conventionalist view in that it approves the role of language in understanding mathematical truths. The social constructivist view tries to understand the metamorphic process of mathematical knowledge and thus is inclined towards the fallibilist view of mathematics. That mathematics is corrigible and is open to change supports the involvement of social dimensions like language in developing mathematics. The social constructivist approach posits the development of subjective knowledge, i.e. individual view, followed by development of objective knowledge, i.e. individual knowledge after social acceptance is considered approved. This transition from subjective knowledge to objective knowledge transits through publication. This publication requires justification on part of the proponent of subjective knowledge. The individual in his process of justification will have to use language to support development of mathematical concepts. Ernest (1991) in his book states that 'the objective criteria for criticizing published mathematical knowledge are based on objective knowledge of language, as well as mathematics'.

Mathematics is the only subject that is privileged to possess its own language. The use of universally known symbols, notations, formulae and procedures followed for solving problems, by itself is unique. What then concerns the teacher and consequently the student in the study of mathematics is the difficulty of understanding these mathematical representations. Once these cyphers are understood, then solving the problem is only an algorithmic task, for example, identifying a number greater by five as against one that is greater than five. 
One commonly asked question while algebra is introduced to the learners is framing equations, given a statement. A question like 'seven less than a number' or 'a number less than seven' often would leave a first timer flummoxed, rather not just a first timer but many learners find it difficult to arrange the terms in the required order. It may not always be the order but the use of the operation also. Terms like 'sum', 'difference', 'product' etc. do not come easily to a student. In order to improve their understanding, use of reasoning is promoted by several researchers. Subramanium (2004) proposes that reasoning about mathematical expressions should be accompanied with reasoning with mathematical expressions. Teaching students only the procedure to be followed for working with an expression (solving an expression) may focus his attention only on procedural information. The use of naming practices could prove beneficial here, under which presentation of names (mathematical terms) that reflect the concept with its hierarchical organization would improve concept learning.

The review of literature lays emphasis on the significance of clarity of language in understanding mathematical concepts, terms, expressions and procedures. Language and mathematics, both support development of cognition and are essential for concept development and consequently thinking. Both language and mathematics are inseparable (Caglar, 2003; Yunus et al., 2004; Silver, 2017; Wilkinson, 2019). Yunus et al. further comprehend that mathematics is not a natural language like French, English and Turkish. Yet mathematics is the common language of science that whole world can understand. According to Galileo, science is written on the very splendid book, which is in front of us, named universe. But we cannot read this book without learning its language and alphabet. This alphabet is mathematics, and without this language, it is impossible to understand even just one word of this book.

The only difference asserted between language and mathematics is the difference in the way it is written. In any language, a sentence comprises of words while a mathematical statement will use symbols. In either case, however, the terms would help associate an idea. For example, when the word 'chair' is used in English class, it will bring to mind the features that characterize a chair, similarly, when the word 'square' is used in a mathematics class, it will associate with the figural representation and the properties of square. Thus, opportunity to allow for expression in mathematics classroom is warranted.

While discussing the role of philosophy of mathematics in designing school curriculum, Tuge (2008), refers to the suggestions by NCTM that in order to develop mathematical habits of mind students should be encouraged to explore, to guess, and even to make and correct errors so that they gain confidence in their ability to solve complex problems; they should read, write, and discuss mathematics; and they should conjecture, test, and build arguments about a conjecture's validity.

Robert Moore in his article "Making the transition to formal proof" states that students encountered some difficulties in learning mathematics when we look at it as a language. He found seven major sources of difficulty:

1. Students did not know or were unable to state definitions;

2. They had little intuitive understanding of the concepts;

3. They had inadequate concept images;

4. They were unable or unwilling to generate and use their own examples;

5. They did not know how to use definitions;

6. They were unable to understand and use mathematical language and notation; and

7. They did not know how to begin proof.

(In Caglar, 2003)

A closer look at the difficulties mentioned above reveal two things. One that students have problem understanding the concepts in math (points 2, 3, 6) and secondly they do not know how to express their understanding (points 1, 4, 5, 7). Understanding mathematical concepts through the use of correct representations is advocated. However, these mathematical representations should be comprehended and expressed by the learner, in order to verify, assimilate and accommodate new relations. Resnick (1998) suggests that using everyday language to talk about a range of mathematical relationships and interpretations may result in more meaningful problem solving. As discussed earlier both mathematics and language support concept development. Teachers should make use of several strategies to ensure the right concepts are formed and further develop skill of expression in mathematics classes as well.

\section{Improving language in mathematics learning}

The following section discusses ways in which mathematics vocabulary of students can be improved. The observations and reflection, as a teacher educator and a guide to student teachers for mathematics subject, have supported the following discussion. Several books have also been referred for determining ways to improve mathematics vocabulary and language, modifying the suggested ideas for implementation in classroom teaching (Bolt, 1982; Murray, 2004; 
Chambers, 2008).

The first suggestion is that the students should be encouraged to speak mathematically. This can be done in several ways.

- After displaying several diagrams of different polygons, ask the students to define polygon in their own words, this will encourage students to study the properties of a polygon and use it for its definition;

- $\quad$ how would he define an 'expression' in mathematics as against the literal meaning of the term 'expression' with an example, this type of comparison will help students verbalize their understanding of 'expression' and also spark interest. Several other terms can also be compared for its mathematical and literal meaning, like perfect numbers, palindromic numbers, friendly numbers, triangular numbers, square or pentagonal numbers;

- $\quad$ allowing the student to express the concept of arithmetic mean in words before eliciting its formula, such sums would help students understand how formula is derived;

- $\quad$ asking the students to differentiate between arithmetic and geometric sequences or finding the similarities between properties of a square and a rectangle and noting them down, such notes will support clarity of concepts.

Students should be asked to express relations through use of concept maps.

- $\quad$ Real numbers, congruency of elements, binary operations, polygons, plane figures or use of syllogisms to express if- then type of sums; i.e., if 12 students play football and 14 students play football and cricket, while remaining 7 do not play either of these sports, find the number of students in the class, such an example will highlight the use of visual representation in mathematics;

- a hierarchical arrangement of understanding polynomials, such a concept map will help students understand how mathematics provides scope for elaboration i.e. developing from a term to monomials to binomials to polynomials;

- $\quad$ concept of lines/rays for explaining different types of angles, again elaboration of ideas will be substantiated.

Brainstorming is another technique that could make students clarify their doubts and express their views without inhibition.

- $\quad$ students could be asked to brainstorm the ideas that come to their mind with the word similarity;

- $\quad$ students could be asked to list the items in the surrounding that are symmetrical and reason for their response, this way they will be able to identify symmetrical elements in nature as also discover the concept of lines of symmetry by themselves;

- $\quad$ they can brainstorm on the shapes that tessellate and why others do not, this will allow for verbal as well as visual exploration.

Use of reflective journals is another way of supporting students' mathematical language. The teacher can ask every student to reflect on his work in the mathematics class and write whether he understood the class discussion and why it interested him. Consequently, if he has not followed anything in class then he should specify the difficulty he experienced in understanding.

The difficulty in understanding mathematical terms is one more area of concern for the mathematics teacher. For example, terms like sum of, difference between, product of, greater than, less by, ratio, congruent are arduous for students to comprehend. This can be helped, by noting down the new terms learnt, after a lesson unit is discussed. At the end of every unit or chapter, new terms can thus be listed. This requires the teacher to be familiar about students' previous knowledge and accordingly introduce the content from simple to complex. It will also help the student to know his level of understanding.

In order to improve students' mathematical vocabulary, the teacher can first develop a worksheet of sums she intends to make her students solve, then make students highlight or underline the operations, words, symbols or relations in the sum or the word problem that he is unable to decipher. The class can proceed from thereon. This will enable the students to identify their strengths and weaknesses.

One more way of helping students learn new terms is by providing them a crossword or a maze. In a crossword, hints that describe the concept or explain an operation could be given to fill the blocks across and down; while in a maze, list of terms can be given which the student crosses as he finds the term in the maze, the word can then be explained by the student in his own words.

Giving students a list of words (mathematical) and asking them to group the words with same meaning will help them understand synonyms of different mathematical terms (e.g. increase, add, multiply, sum, plus, greater by). On the same lines making students find the 'odd man out', when a set of grouped words are given can also produce the same results. 
Use of match the columns can also be of significance in supporting students development of vocabulary in mathematics, for example, one of the columns could include description of a term or a concept and the second column would include the name of the concept or term.

Another strategy that the mathematics teacher can use is to allow students to frame questions, when the solution is provided. For instance, the teacher can give an equation $7 x+5=19$, and the student is expected to frame a statement in order to get the required equation. Similarly, students could be asked to frame questions based on concepts of profit and loss or Pythagoras theorem also. This is a very effective approach in supporting students' concept development, as the student will have to use a means-end analyses approach here. In order to obtain a desired response, he has to now verbalize the conditions and variables and relate them appropriately.

Improvement in students' mathematical language can also be achieved by improving their comprehension of a word problem. Encouraging students to frame their own word problems would support their use of mathematical terms and language appropriately. For example, age related word problems could be framed by students by asking them to compare their own age with that of their parent. This will support their understanding of relationships in a word problem. Since, in several researches, it is concluded that it is generally the inability of a student to understand the correlation among the variables in the word problem, i.e., their inefficiency in synthesizing the information that leads to difficulty in solving word problems (Smith \& Kepner, 1981). Also relating it to real life situations will make the applicability of the subject also evident.

None can refute the role of mathematical riddles and puzzles in developing logical thinking and analytical skills. The mathematics teacher can also make use of such small intercepts in the class, but with the students making and asking the riddles instead of the teacher giving them. Framing such riddles would require the students to understand and express relation among different mathematical concepts. This will encourage students to use mathematical terms in meaningful ways, thus ensuring retention of concepts.

Allowing students to explain a concept in poetic form could work wonders in concept clarification. Great mathematicians like Aryabhatta have compiled volumes explaining mathematical ideas poetically. A math teacher should allow for such ventures in her class. For instance, if a student writes a poem on 'numbers' or 'ratio', it could definitely make him look forward to attending a mathematics class and consequently make the subject more pleasing. Just like encouraging poems the teacher could also make a student write essay on topics like 'fractions' or 'imaginary numbers'. Such simple activities could develop appreciation for the subject and support meaningful learning.

\section{Concluding Remarks}

Every mathematics teacher should seek an answer to the elusive nature of students towards studying mathematics. The paper tries to address this issue by giving suggestions to improve the classroom interaction, in the light of policy recommendations.

This entails that learners should be allowed to express their understanding of mathematical terms, concepts or relationships in their own words. They should be encouraged to speak mathematically. Use of concept maps, brainstorming sessions, reflective journals, keeping a list of mathematics vocabulary, i.e., new terms (concepts) studied in a particular unit, promoting writing of essays or poems on mathematical ideas could be used by mathematics teachers just as is used by language teachers. Underlining key terms or phrases when a worksheet is provided to learners, focusing on generating word problems when the solution is provided for, use of the means-end analysis, i.e., moving from the goal to given data, thus eliminating superfluous information required for problem solving, data sufficiency questions, framing multiple choice questions, use of learners previous knowledge and contextual information would all support development of conceptual learning of mathematics.

As a teacher of mathematics one cannot overlook the role of improving mathematics vocabulary and language, of students. Though mathematics has its own universally accepted language, it has to be first learnt and communicated through the spoken language that the student is familiar with. As noted earlier, the inability in understanding mathematics concepts due to lack of complete knowledge of mathematical terms cause students to abhor the subject. This needs to be surmounted gradually with an aim to reducing the burden of studying among students.

\section{References}

Bolt, B. (1982). Mathematical Activities. Cambridge: Cambridge University Press.

Caglar, M. (2003). Mathematics and Language. The Turkish Online Journal of Educational Technology, 2(3), 48-55.

Chambers, P. (2008). Teaching Mathematics. Sage: New Delhi. 
Department for Education and Employment. (1999). The National Curriculum for England: Mathematics. London: HMSO.

Ernest, P. (1991). The Philosophy of Mathematics Education. E-lib: Taylor \& Francis.

Murray, M. (2004). Teaching Mathematics Vocabulary in Context. Portsmouth: Heinnemen.

NCERT. (2005). National Curriculum Framework. Delhi: NCERT.

Resnick, L. B. (1998). Treating mathematics as an ill-structured discipline. In Charles \& Silver (Eds.), The teaching and assessing of mathematical problem solving. NJ: Lawrence Erlbaum.

Schoenfeld, A. H. (1992). Learning to think mathematically: Problem solving, metacognition and sense-making in mathematics. In D. Grouws (Ed.), Handbook for Research on Mathematics Teaching and Learning (pp. 334-370). New York: MacMillan.

Scopes, P. (1973). Mathematics in Secondary Schools. Cambridge: Cambridge University Press.

Silver, D. (2017). The New Language of Mathematics. American Scientist, 105(6), 364. doi: 10.1511/2017.105.6.364.

Smith, C. and Kepner, H. (1981). Readings in the Mathematics Classroom. Washington: National Education Association.

Subramaniam, K. (2004). Naming practices that support reasoning about and with expressions. Proceedings of the international congress on mathematics education (ICME 10), Denmark.

Tuge, C. (2008). Mathematics curriculum, the philosophy of mathematics and its implications on Ethiopian schools mathematics curriculum. Ethiopian Journal of Education \& Science, 4(1), 109-120.

Wilkinson, L. (2019). Learning language and mathematics: A perspective from Linguistics and Education. Linguistics and Education, 49, 86-95. doi: 10.1016/j.linged.2018.03.005.

Yunus, A., Oktay, Y., and Ahmet, I. (2004). Mathematics and Language. Research in Mathematical Education, 8(1), 31-37. 